\title{
Energy, Social and Economic Indicators for Evaluation of Retrofit Buildings: The Brazilian Perspective on Sustainable Development
}

\author{
Mauro Donizeti Berni ${ }^{1}$ and Paulo C. Manduca ${ }^{1,2}$ \\ 1. Interdisciplinary Centre on Energy Planning, University of Campinas, Campinas 13083-896, Brazil \\ 2. Instituto de Ciências Jurídicas, Universidade Paulista, Campinas 13030-370, Brazil
}

\begin{abstract}
This paper aims to establish a methodological frame work and its validation as a response to the need of a demand management tool in the face of recurring comparisons of building revitalization or retrofits. As the investment and implementation actions improve and the social economic criteria are delimited by regulatory frameworks, it is extremely necessary to monitor previous performances and further prospects, regarding projects, it is necessary to measure the extent of which efforts have been meeting regulatory requirements and aiming to contribute with sustainable development. In this context, the use of indicators has been a major management tool.
\end{abstract}

Key words: Retrofit building, economic indicators, social indicators.

\section{Introduction}

This study evaluates the regulatory framework and its interrelation concerning the necessary preliminary studies for the revitalization viability projects or retrofits real state in a sustainable manner, focusing on social and economic dimensions. Regarding the sustainability of the noted social perspective, emphasis is given due to the presence of humans in the biosphere. The major concern is the welfare, the human condition and the means used to increase its life quality. Access to basic services, clean and treated water, clean air, medical services, protection, safety and education may or may not be related to the society's income or wealth. Social sustainability refers to a development process that leads to a stable growth with equitable income distribution, which resulted in decreasing the current differences between the various levels of society and improving the populations' living conditions.

Corresponding author: Mauro Donizeti Berni, Ph.D., research fields: energy efficiency, smart grid, regulatory politics and global governance on biofuels. E-mail: mberni@unicamp.br.
Economic sustainability includes allocation and efficient distribution of resources within an appropriate scale. The concept of sustainable development is not restricted to conventional monetary or economic capital, but it is open to the consideration of different types of capital including the environmental, human and social.

The following sections present an alternative methodology and its validation in the context of sustainable retrofit of buildings of social and economic indicators establishing a baseline for sustainability in buildings. Indicators are important tools for multiple and varied information processing, allowing a simple graphical form, the translation of complex realities and decision-making. Correct decisions in the building's design phase can result in lower social and environmental impacts, and therefore more sustainable ones. Green seals and/or quality certificates are certificates of compliance with regulatory frameworks yet in the design, construction, deconstruction and/or quality to ensure the lowest social and economic impact as well as lower energy consumption for 
building or built “retrofit” the old building.

\section{Social Indicator in Retrofit}

Social indicator is in general a quantitative measure endowed with a social meaning noun, used to replace, quantify or operationalize an abstract social concept of theoretical or programmatic interest. It is a methodological, empirically above, that tells something about an aspect of social reality or on changes that are taking place in the same.

In assessing the living conditions in a particular building, it can be operationally translated as the level of care the basic material needs for survival and social reproduction. Thus, the operational dimensions of interest might be the health conditions, housing type and quality, infrastructure, urban services, accessibility, safety, etc.. Another important aspect is the classification and criteria for choosing social indicators. Because of conceptual differences, social indicators can be subjective and objective, despite being in the same social dimension, can not point the same trends. For example, in the investigation of a typology as a residential housing program, it is quite possible that the objective indicators point improvement over the material conditions in life, which, as a matter of fact, does not manifest itself in satisfaction indicators based on a survey made with people who live there.

Social indicators covering the post-occupancy evaluation of these types are being used to identify strengths and weaknesses on decisions taken in the project design phase and can be used in the design process of new ventures. It consists of a broad diagnosis of the built environment, including building system analysis, environmental comfort, functionality, accessibility, fire safety and the relationship between the built environment and the user.

Considering the various actors that make up the market forces, as well as the goals of the entrepreneur in the construction industry functionality, with the necessary security conditions for the effects of both natural and human actions and durability features that enable the reduction of deterioration throughout its life cycle and costs involved, the proposed methodology led to the selection of the following social indicators:

- Employment practices: In regard to labor practices, the authors suggest indicators such as employment, health and safety, training and education, diversity and equal opportunities:

(1) Employment: discrimination of total manpower, by type of employment, work contract and by region, or total number of employees and its turnover rate, by age, gender and region;

(2) Health and safety in the workplace: rate of injuries, occupational diseases, lost days, absenteeism and work-related deaths by region, or educational programs, training, prevention and risk control to provide assistance to workers, their families or community members;

(3) Training and education: average hours of training per year per employee broken down by category of functions, or programs for management skills and lifelong learning that support the continued employability of workers and career management;

(4) Diversity and equal opportunities: organization chart of the company's management staff and respect of towards employees per category according to gender, age and minorities, or basic salary breakdown for men and women by the employee's function category;

- Human rights: Performance indicators regarding human rights must be related to investment practices in the selection of suppliers and contractors:

(1) Discrimination: total number of discriminatory incidents and actions taken to its abolition;

(2) Abolition of child labor: number of cases where there is a significant risk for child labor incidents and measures to contribute to its elimination;

(3) Prevention of forced and slave labor: number of cases where there is a significant risk for incidents of forced or compulsory labor and measures that contribute to its elimination;

(4) Safety procedures: percentage of security personnel who underwent training in company policies 
or procedures, human rights and which are relevant to such operations;

- Society: Company's indicators are focused on the impacts of the entrepreneur and the construction type, and/or constructed or not, are produced in the communities where it operates and how the disclosure of the risks resulting from their interaction with the society are managed dealt with and mitigated [1]:

(1) Community and users: nature, scope and effectiveness of any programs and practices which evaluate and manage the impacts of works on communities, including the installation time, operation and demobilization period;

(2) Corruption: percentage of workers who have attended educational policies and done company's anti-corruption practices or even been caught by "actions taken in response to corruption incidents";

(3) Public policy commitment and participation of public policy development as well as pressure groups [2];

- Unfair competition: Total number of lawsuits for unfair competition, monopoly practices and their corresponding results;

- Responsibility: Social responsibility indicators are essentially related to the quality and marketed product:

(1) Consumer's health and safety: indicators concerning the life cycles of products and services in the determined health and safety impacts in order to promote continuous improvement;

(2) Marketing communications: programs for adherence engaged to laws, standards and voluntary codes related to marketing communications, including advertising, promotion and sponsorship;

(3) Customer's privacy: total number of substantiated complaints regarding breaches of customer's privacy.

\section{Economic Indicator in Retrofit}

Projects must have clear objectives and when they are in progress they should be evaluated by operational indicators beyond impact, effectiveness and performance for possible fixes your route. Work "by design” is extremely pragmatic, after all, every project is a temporary endeavor-finite period, which regards material, logistical and human resources, to mention some, and therefore requires prior budget and financial investment management. Thus, in a given period, a product or service is generated based on a defined budget.

In the project area, there are gaps that require immediate action of the directors and project managers, with emphasis on performance indicators. In manuals published by the U.S. PMI (Project Management Institute) lies the following definition of project risk: uncertain event or condition that, if it occurs, will have a positive or negative effect on at least one project objective, out of time, cost, scope or quality-PMI PMBOK Guide [3]. The type of risk and its probability of occurrence or its impact on the project varies throughout the life cycle of the same, so identification of risks, in all its phases is necessary.

The discussion that follows is about monitoring the project during the life cycle of a building [4]. In the project area, among the indicators, there is a discussion about CPI (cost performance index) and SPI (schedule performance index), which respectively represent: the performance index on a project cost and the scheduled performance index in of the project, based on the implementation of planned activities and incurred costs. There are, however, four types of important design indicators that must be viewed repeatedly, namely impact, effectiveness, performance and operational. The impact indicator measures the project's overall objective with long-term results and its contributions to the organization, the effectiveness indicator measures the results of the proposed objectives in a given period of time. As for the performance indicator, the planned results are achieved by citing ROI-return of investment (including the traditional net present value, internal return rate and payback), CPI and SPI are obtained at the end of the project. 
The earned value analysis and earned value analysis [5] builds on the fundamental formulas earned value-BAC (budget at competition), actual cost, value and planned value-to determine project performance, cost and relative scheduled rates. The value is part of the cost control process group of cost management project. Valued formulas for performance purposes are: CPI-representing the amount of work being done on a project for each unit cost spent. The $\mathrm{CPI}$ is calculated by the ratio value $(\mathrm{EV})$ and spent actual value (AC), i.e., EV/AC. A value above 1 means that the project is coming within the budget. The SPI represents how close to the schedule the current work is being completed. The SPI is calculated by the ratio value (EV) and planned value (PV), i.e., EV/PV. It compares the cost of which was gained to what has been estimated. A value above 1 means that the project is aligned with the proposed timetable.

The EVM (earned value management) is a technical project management to measure performance and progress in an objective way. EVM has the ability to combine scope measurements, schedule and cost in a single integrated system. The essential features of any implementation of EVM include: a project plan that identifies the work to be completed, the job evaluation plan called PV (planned value) or the BCWS (budgeted cost of work scheduled) and preset "earning rules" (metric rules) to quantify the work, called EV (earned value) or BCWP (budgeted cost of work performed). The implementation of EVM for large and complex projects includes additional features such as indicators and trend forecasts in costs and performance budget. However, the most basic requirement of an EMV system is that it quantifies progress using PV and EV.

Payback is a practical investment analysis method which sets the time for investment return. The payback is the relationship between the investment and cash flow of the project [6]. The turnaround time indicates within how long the recovery should occur on the investment. The weaknesses of this method are: (1) it does not consider the time value of money; (2) it does not consider cash flows after capital recovery; and (3) it can not be applied when the cash flow is not conventional. The analytical methods are accurate-based on the value of money in time. The value of money over time for each firm is expressed by a parameter called minimum rate of appeal. This rate is specific to each company and represents the rate of return that it is willing to accept a risky investment - business plan- to give up a certain return on a riskless investment in the financial market. The analytical methods used in investment analysis are NPV (net present value) and internal rate of return [6]. The NPV, the internal return rate and the index $=$ ROI net income/investment represent the return that particular investment offers and is often used to determine the return of an investment alone. By inverting the relation ROI = investment/net income, the authors obtain the time needed to get the money back.

It is noted that the main difficulty in the investment analysis is to obtain reliable data, particularly the forecasts for cash inflows [7]. They arise primarily from the revenue estimates. When they are inaccurate, it is recommended that the investment analysis uses three scenarios: likely, optimistic and pessimistic. Thus, the investment analysis will produce an internal return rate and a net-present value maximum, average and minimum expected. The method of investment analysis presented, in which the data is considered to be certain, it is called deterministic. The internal return rate and the net-present value can be improved by more sophisticated techniques (e.g., Monte Carlo analysis) to deal with risk and uncertainty related to the project data.

\section{Energy Efficiency Indicator in Retrofit}

According to project LEHR [8], up to 35\% of the total energy consumption can be attributed to buildings. Consequently the renovation of existing buildings contributes a vast potential for energy economy. Energy buildings requirements in the economy, depend on the region, and are therefore of strategic importance 
in reducing greenhouse gas. Retrofit improvements to the heating and cooling systems of existing homes and their thermal envelope (e.g., by increasing insulation levels and reducing air leakage) present major opportunities for cost-effective investments in efficiency. Indeed, roughly half of all efficiency and/or carbon emission reduction potential in Brazil buildings is associated with retrofit improvements to existing homes.

Energy efficiency improvements represent a small fraction of the total costs of new construction or equipment purchases. For retrofit projects, efficiency improvements may account for most or all of the work, and thus for most or all of the cost. It is also technologically easier and less expensive to do something right the first time (during new construction) than to fix it later (as a retrofit). Treating existing buildings requires detective work [9]. Unlike in new construction, retrofit contractors are typically not familiar with the buildings on which they will work. Nor do retrofit contractors typically start with building plans that they can study. A diverse building stock also requires retrofit contractors to be knowledgeable about a range of construction practices.

There are opportunities to improve the energy efficiency of buildings at each stage in the building's life (Fig. 1). At each stage, barriers to energy efficiency must be overcome in order to achieve the full economic potential of energy efficiency. Today, a number of policy options are being developed around the world to tackle each of these barriers. These policies will help

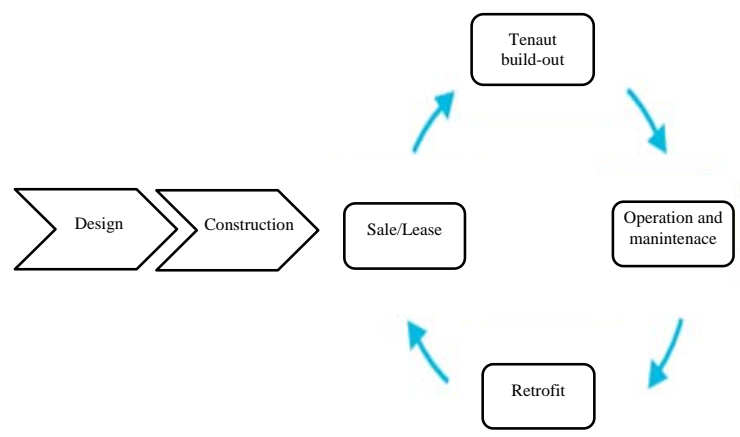

Fig. 1 Lifecycle of a building [10]. bridge the efficiency gap, enabling critical actors in the market to make decisions that favor energy efficiency. Each country or city must map their own policy pathway to transform the built environment in a way that is most appropriate for them.

\section{Conclusions}

As for remarking and enhancing the fragile public policy, aiming at sustainability in the construction industry in Brazil, the industry's main goal is to determine such sustainability indicators. On the other hand, it is necessary to emphasize that there is often some kind of misunderstanding between the issues and the sustainability certifications. This work also intended to help minimize interpretation comprehension mistakes, whose efforts are focused on the development method for establishing national sustainability indicators for several typologies.

\section{Acknowledgments}

The authors would like to thank FAPESP (São Paulo Research Foundation) and IYO Sustainable Solutions Ltda. for sponsoring this essay.

\section{References}

[1] A.E.O. Borba, Sustainability indicators proposal to the civil construction sector, Master Dissertation, Polytechnic School, Federal Universityof Pernambuco, Brazil, 2009, p. 135. (in Portuguese)

[2] A. Miguel, Gestão Moderna de Projectos, 4th ed., FCA Publisher, Portugal, 2010.

[3] PMBOK Guide, 4th ed., Project Management Institute-PMI, Filadélfia, USA, 2008.

[4] C.A.C. Ribeiro, C.G. Camargo, Productivity programs in public sector: Discussionof some basicelements, Journal of Indicators of Quality and Productivity, Institute for Applied Economic Research 2 (1) (1994) 67-78. (in Portuguese)

[5] R. Vargas, Análise de Valor Agregado em Projetos, 4th ed., Brasport Publisher, Rio de Janeiro, 2009.

[6] S.A. Ross, R.W. Westerfield, J.J. Jaffe, Administração Financeira: Corporate Finance, Atlas Publisher, São Paulo, 2002.

[7] J. Toledo, Produção, Produtividade e Eficiência, 8th ed., I. Fides Publisher, São Paulo, 2004.

[8] W. Hilderson, E. Mlecnik, J. Cré, Potential of Low Energy 


\section{The Brazilian Perspective on Sustainable Development}

Housing Retrofit: Insights from Building Stock Analysis, The Belgian Science Policy, 2010, http://www.belspo.be/ (accessed Nov. 1, 2012).

[9] C. Neme, M. Gottstein, B. Hamilton, Residential Efficiency Retrofits: A Roadmap for the Future, Montpelier, Vermont 05602, Brussels, Belgium, May
2011, p. 68.

[10] K. Managan, M. Araya, J. Layke, Driving Transformation to Energy Efficient Buildings: Policies and Actions, Business Council for Sustainable Energy, Center for Clean Air Policy, U.S. Green Building Council, and World Green Building Council, Dec. 2011, p. 92. 